\title{
Defining of eligible capacity for biomass cogeneration plants in small towns in Estonia
}

\author{
A.Volkova ${ }^{1}$, A. Hlebnikov ${ }^{1}$ and A.Siirde ${ }^{1}$ \\ ${ }^{1}$ Department of Thermal Engineering \\ Faculty of Mechanical Engineering \\ Tallinn University of Technology \\ Kopli 116, 11712 Tallinn, Estonia \\ Phone numbers: +372620 3907, +372 6203638 Fax number: +372620 3901,

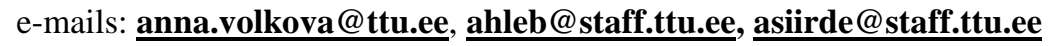

\begin{abstract}
There is a high potential for small-scale and medium scale biomass cogeneration in Estonia. It can be explained by high heat loads in household sector and large availability of biomass energy sources.

During the research an eligible size for biomass cogeneration capacity in Estonian small towns was defined. Estonian conditions were taken into account: local energy sources, fuel and electricity prices, cold climate, state of local district heating systems, Estonian legislation and support mechanisms for cogeneration plants.
\end{abstract}

Heat load duration curves for four Estonian small towns with heat load 5-20 MW were taken as a base for smallscale and medium-scale cogeneration potential.

Partial load cogeneration optimal sizing was researched in this paper. Results were checked and approbated by economical and environmental factors.

\section{Key words}

Combined heat and power, district heating, small-scale cogeneration, biomass, primary energy efficiency

\section{Introduction}

Cogeneration technology provides greater conversion efficiency than traditional generation methods as it harnesses the heat that would otherwise be wasted. This can result in up to more than a doubling of thermal efficiency. Fuel consumption can be reduced, which results in reduction of carbon dioxide emissions.

The potential for using cogeneration as a measure to save energy sources is in the focus of attention in the EU at present time, according to EU Directive 2004/8/EC on the promotion of cogeneration based on a useful heat demand on the internal energy market. Promotion of high-efficiency cogeneration (CHP) based on a useful heat demand is a Community priority given the potential benefits of CHP with regard to saving primary energy, avoiding network losses and reducing emissions, in particular of greenhouse gases. [1]

Estonia is the member state of the European Union and has a high potential for CHP development. The Estonian vision, according to the "Energy Sector Development Plan 2020" is that up to $20 \%$ of electricity should be produced by cogeneration plants. [2]

Wood, biomass and biogas can be used for electricity production in cogeneration plants. But there are no smallscale (<1MWel) and medium scale (1-20 MWel) cogeneration plants based on biomass in Estonia.

The main reasons to develop biomass small scale and medium scale cogeneration in Estonia are necessity for additional energy sources, wood resources availability and high potential for small-scale and medium scale cogeneration development in Estonian small towns.

The purpose of this research is to define the eligible capacity for biomass cogeneration plant operating on the base of district heating systems in small towns.

\section{Small-scale and medium scale cogeneration potential in Estonia}

High potential for small-scale and medium-scale cogeneration in Estonia can be explained by various factors. One of the main factors is the heat load in household area, which can be covered by heat produced by cogeneration plant. High heat loads in Estonian towns are explained by long and cold winters and cold climate in Estonia. The district heating systems are typical for small and big cities in Estonia. [3] 
In Estonia there are only 15 towns with population exceeding 10000 inhabitants and there are also 181 administrative units with population ranging from 1000 to 10000 inhabitants. Small-scale and medium-scale cogeneration systems can be used in the small towns.

There are many small towns in Estonia where boiler houses should be renovated. During renovations the new boilers can be installed, the type of fuel can be changed or the new alternatives with cogeneration technologies can be used.

Biomass cogeneration can be one of the alternatives for renovation or development of district heating systems. It is very important to choose an eligible size for the installed technology.

\section{Optimal Sizing of Cogeneration}

Before installation of a new cogeneration plant, an energy producer faces the basic question of how high a station's installed capacity should be. Due to the fact that cogeneration produces heat and power, it becomes crucial for both types of energy to be used appropriately. As concerns power, it may both be used on the spot and transported across great distances; heat, however, may only be used in the vicinity. Thus, the heat energy consumer is considered the main factor in selecting cogeneration plant capacity. The risks of installed cogeneration capacity are related to two scenarios: if a load is used that exceeds the optimum setting, the station will not be able to operate year-round due to insufficient heat load, while, should the load be installed below optimum, the potential of utilising heat capacity will not be fully used.

As it has just been mentioned, heat consumer is the main factor for cogeneration capacity optimisation, that's why the sizing should start with an assessment of consumer heat load. The optimal technology and facility capacity for cogeneration are selected based on the amount of heat demanded by consumers. Heat load values for residential buildings and load prevalence during the year are visualised by heat duration curve (Figure 1).

There are different heat duration curve based approaches described in several references.[4]-[6]

The approach used in previous research included maximizing of year-round amount of heat while working at full installed capacity. This means that the facility's capacity will be determined by the rectangle of maximum size that can be inscribed in the heat duration curve. Division of each hour's load values by the maximum load value yields a normalised or relative load curve. [6]

Another approaches to installation include the following: the reduced-scale sizing, when the rated thermal power of a cogeneration unit is diminished while the annual use is increased; the partial-heat-usage sizing, when cogeneration extends its use to periods of lower heat demand and in this case a part of the generated heat is not used; the multiple cogeneration units, when instead of a single unit the separate cogeneration units are used; and finally, when cogeneration is operated at partial loads. During this research is realized an optimal sizing for biomass cogeneration plants by the partial load cogeneration.

Steam turbines are the most appropriate for the smallscale and the middle-scale cogeneration plants based on biomass. Steam turbines can operate with high common efficiency when the load is higher than 75\%. [7]-[9]

It was assumed that the cogeneration plant operates by heat load lower than full installed cogeneration capacity; the plant stops to operate when the load becomes lower than $75 \%$ from the installed cogeneration capacity. The main factor compared for different installed capacities, is the annual electricity production by cogeneration.

Four small towns in Estonia were chosen for evaluation: Kiviõli, Keila, Jüri and Tabasalu. Heat duration curves were built for these towns (Figure 1). As the Figure 1 indicates, the maximum capacities are different: $20 \mathrm{MW}$ for Kiviõli, 21 MW for Keila, 8 MW for Jüri and 5 MW for Tabasalu. The heat load changes in the same way for all towns, the only difference is the heat load scale.

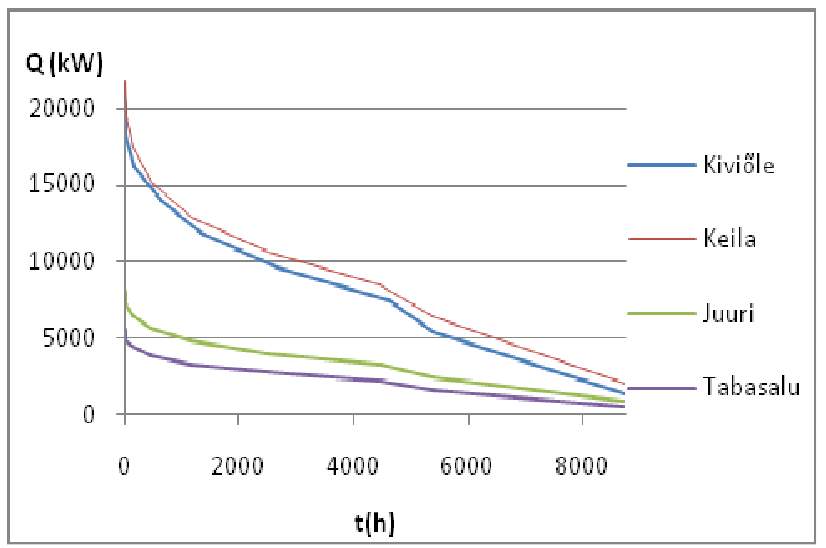

Fig.1. Heat load duration curve for Kiviõli, Keila, Jüri and Tabasalu

According to the Figure 1 the high spikes are typical for the heat load duration curve. These spikes are explained by fact, that there are some especially cold days during the winter period in Estonia. These spikes are typical for Nordic countries such as Finland and Sweden. Heat load duration curve is more gradual for other countries.

Relative load curves were constructed by division of each hour's load values by the maximum load value (Figure 2). All data were approximated. Regression equation is following:

$r_{Q}=-4 \cdot 10^{-12} t^{2}+5.4 \cdot 10^{-8} t^{2}-2.9 \cdot 10^{-4} t+0.895$

where

$\boldsymbol{r}_{\boldsymbol{Q}}$ is relative heat load [dimensionless quantity];

$t$ is time per year [h].

Regression function is displayed on Figure 2.

The squared correlation coefficient is high $\left(\mathrm{R}^{2}=0.964\right)$ and therefore the function (1) describing the relative heat 
duration curves for the four towns is very close to real situation.

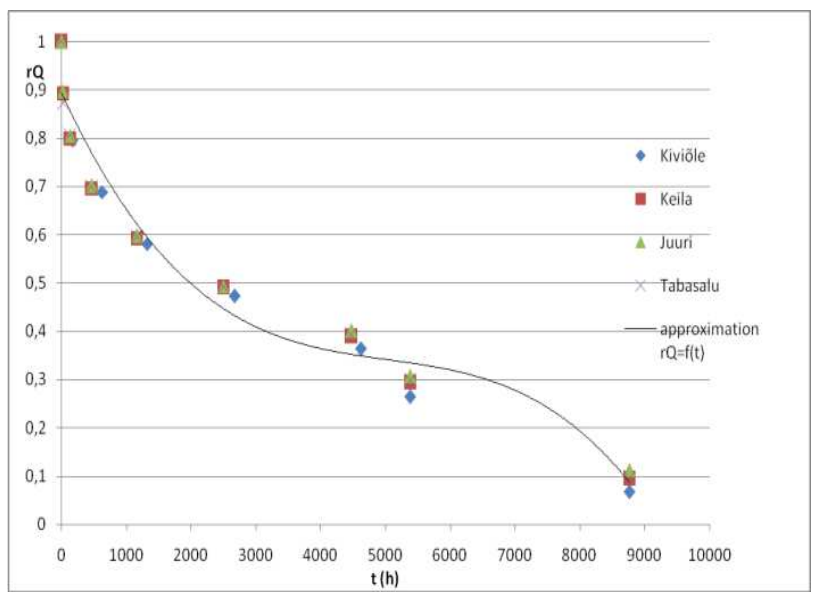

Fig.2. Normalised heat load duration curves and approximation

Method of year-round amount of heat maximizing while working at full installed capacity supposes that the optimisation criteria is calculated by equation (2)

$$
Q_{r}=r_{Q} t
$$

where

$Q \boldsymbol{r}$ is relative heat, produced by cogeneration, shows what part from annual heat ammount is produced by cogeneration plant $[1 * \mathrm{~h}]$, optimisation criteria.

According to calculation the maximal value of Qr is equal to $1970.531 * \mathrm{~h}$ and it is located in the point where $r_{Q}$ is 0,298 . It means that in the case when the cogeneration plant is operating only with maximal capacity, the optimal size for installed capacity is $29.8 \%$ from the maximal heat load. Optimal criteria dependence on relative heat load is shown in Figure 3 with a dash line.

But this method is appropriate for the situation, when cogeneration plant operates with maximal load; in case load becomes lower than the installed cogeneration capacity the plant should be switched off.

Using above mentioned assumption, that cogeneration plant continues operation till heat load is lower than $75 \%$ from installed cogeneration capacity, it is calculated, that installed optimal capacity for cogeneration plants can be $75 \%$ from maximal heat load for consumer.

For calculation of heat produced by cogeneration, when plant is operating both with maximal and with partial loads, equation (3) is used.

$$
Q_{r}=r_{Q} t_{Q}+\int_{t_{0,75 Q}}^{t_{Q}} f(t)
$$

\section{where}

$\boldsymbol{f}(\boldsymbol{t})$ is equation (1);

$t_{Q}$ is number of hours, when consumer heat load is higher, than installed cogeneration capacity $[\mathrm{h}]$; $\boldsymbol{t}_{0.75 \mathrm{Q}}$ is number of hours, when consumer heat load is higher, than $75 \%$ from installed cogeneration capacity $[\mathrm{h}]$.

According to calculation the maximal value of $\mathrm{Qr}$ is equal to $2468.691 * \mathrm{~h}$ and is located in the point where $\mathrm{r}_{\mathrm{Q}}$ is 0,377 . It means that in the case when the cogeneration plant is operating both with maximal and partial loads, the optimal size for installed capacity is $37.7 \%$ from the maximal heat load. Optimal criteria dependence on relative heat load calculated by offered method is shown in Figure 3 with a solid line.

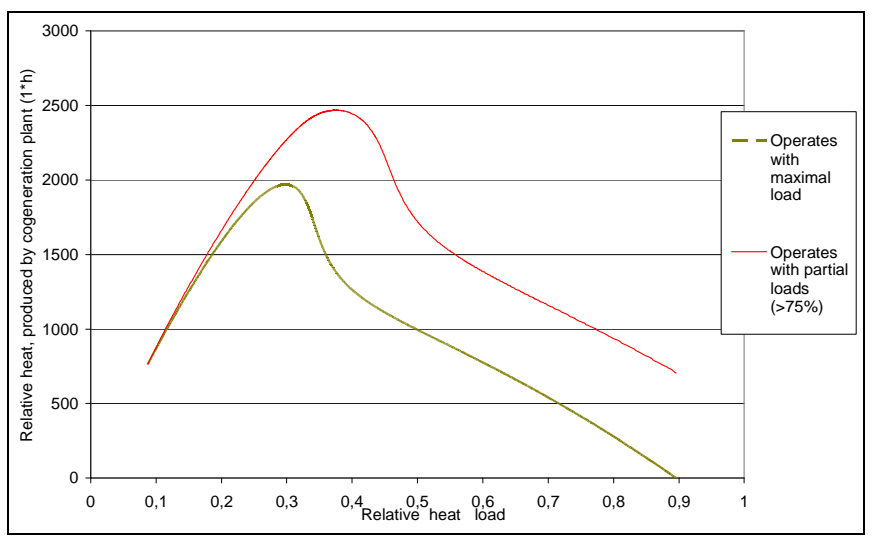

Fig.3. Comparison of optimisation criteria, calculated for cogeneration plant operating with maximal and partial loads

This method shows that installed capacity can be higher and plant can operate longer during the year and produce more electricity. Electricity production by cogeneration for four small towns in case of using optimal sizing is shown in Table 1.

Table 1 Electricity produced by cogeneration plant with optimal capacity

\begin{tabular}{|l|r|r|}
\hline \multirow{2}{*}{ Town } & \multicolumn{2}{|c|}{$\begin{array}{c}\text { Electricity produced by cogeneration } \\
\text { plant with optimal size (MWh) }\end{array}$} \\
\cline { 2 - 3 } & $\begin{array}{l}\text { Cogeneration plant } \\
\text { operates with } \\
\text { maximal load }\end{array}$ & $\begin{array}{l}\text { Cogeneration plant } \\
\text { operates with } \\
\text { maximal and } \\
\text { partial loads }\end{array}$ \\
\hline Kiviõli & 8027,71 & 10056,95 \\
\hline Keila & 8569,61 & 10735,84 \\
\hline Jüri & 3165,13 & 3965,21 \\
\hline Tabasalu & 2171,57 & 2720,50 \\
\hline
\end{tabular}

The table indicates, that electricity amount produced by cogeneration including partial loads is much higher.

Using this method it is possible to realise optimal sizing for cogeneration plant from the technical point of view. As a result of sizing, a cogeneration plant is chosen, 
which can produce maximal heat and electricity in cogeneration mode. But usually the main factor for cogeneration plant owner is the economical factor. This factor is the most significant for choosing the cogeneration plant size; therefore economical approbation is necessary for method validity check.

One of the most popular indicators for projects is NPV (net present value), which indicates how much value an investment or project adds to the enterprise. In case of $\mathrm{NPV}>0$ the investment will add value to the enterprise. If different projects are compared, then the project with higher value is chosen.

Following data were used for calculations: data about annual heat load in the towns (data from municipalities); power to heat ratio was assumed as 0.22 , total efficiency 0.88 , investment amount was normalised for each case based on calculations realised during the previous research (1200-1600 EUR/MWel); heat price was defined as $50 \mathrm{EUR} / \mathrm{MWh}$ (for producer), electricity price was defined as 73,56 EUR/MWh (feed-in tariff for green electricity, defined by Estonian Electricity Market Act); wood chips were assumed as a fuel with fuel price 10EUR/MWh [10], other operation costs were added too.

As a result the net present value for 10 different capacities was calculated for 4 towns in case cogeneration plant was operating both with maximal and partial loads. Calculation results are shown in the Figure 4.

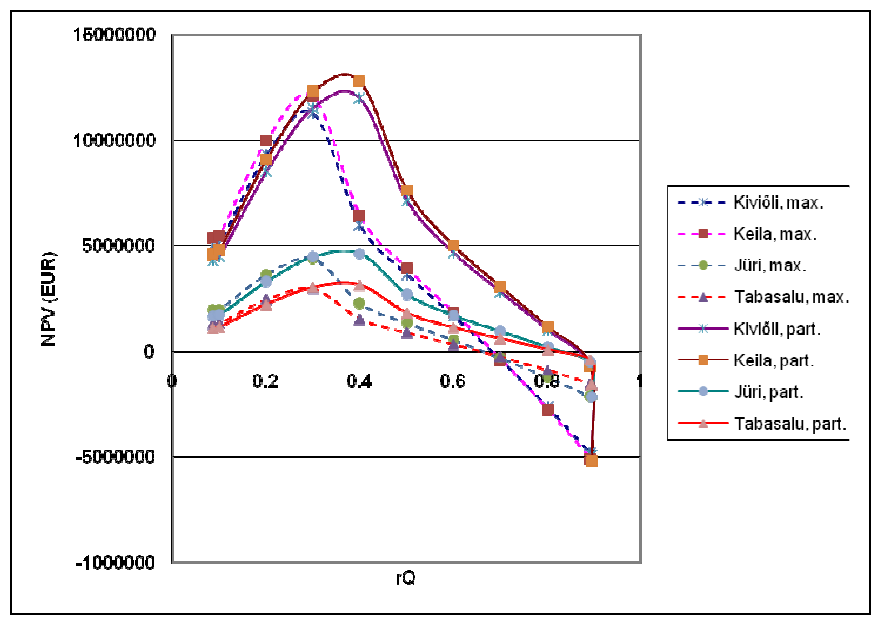

Fig.4. Economical approbation of optimal sizing with partial loads method

It can be seen that maximal NPV for cogeneration plants, which are operating only with maximal capacity is achieved when cogeneration plant installed heat capacity is approximately $30 \%$ of maximal heat load. But when cogeneration plants are operating with partial loads (>75\%) maximal NPV is achieved by installed heat capacity being approximately $40 \%$ from maximal consumer heat load.

Besides economical and technical factors the environmental factors are also significant. Wood chips consumption for heat and electricity production is a very positive environmental factor, because it reduces fossil fuel consumption for energy production. But wood chips are a natural energy source, that's why combined producing of heat energy and electricity allows reducing wood fuel consumption in comparison with separate energy producing.

EU Directive 2004/8/EC on the promotion of cogeneration based on a useful heat demand in the internal energy market and Estonian Requirements for Efficient Cogeneration define the methodology for calculation of primary energy saving in cogeneration process.

$$
P E S=\left\{1-\frac{1}{\frac{C H P H \eta}{R E F H \eta}+\frac{C H P E \eta}{R E F E \eta}}\right\} 100 \%
$$

where

$\boldsymbol{P E S}$ is primary energy savings, \%

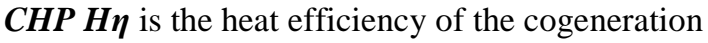
production;

$\boldsymbol{R} \boldsymbol{e f} \boldsymbol{H} \boldsymbol{\eta}$ is the efficiency reference value for separate heat production;

$\boldsymbol{C H P E} \boldsymbol{E} \boldsymbol{\eta}$ is the electrical efficiency of the cogeneration;

$\boldsymbol{R e f} \boldsymbol{E} \boldsymbol{\eta}$ is the efficiency reference value for separate electricity production.[10]

According to Estonian Requirements for Efficient Cogeneration efficiency, the reference value for separate heat production based on wood fuel is 0,86 , but efficiency reference value for separate electricity production based on wood fuel for period 2006-2010 is 0,34 . [11]

After modifying the equation (4) it is possible to define primary energy saving in natural units by equation (5)

$\Delta B=\left\{1-\frac{1}{\frac{C H P H \eta}{R E F H \eta}+\frac{C H P E \eta}{R E F E \eta}}\right\} \cdot\left\{\frac{W}{R E F E \eta}+\frac{Q}{R E F H \eta}\right\} \div L H V^{(5)}$

where

$\Delta B$ is primary energy savings, $\mathrm{t}$

$W$ is annual electricity from cogeneration, MWh;

$Q$ is annual heat from cogeneration, MWh;

$L H V$ is net caloric value, $\mathrm{MWh} / \mathrm{t}$.

Results of calculation for each town are shown in the Figure 5. The figure shows wood fuel saving for cogeneration plants with capacity defined by optimal sizing in case cogeneration is operating with maximal load and with partial loads. As it can be seen primary energy saving is also higher when cogeneration plant operates with partial loads. 


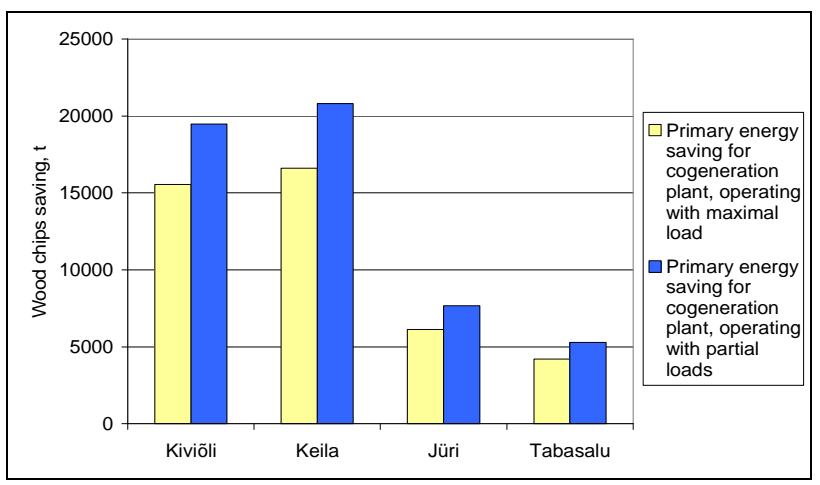

Figure 5 Cogeneration plant primary energy saving in comparison with separate heat and power production

\section{Conclusions}

Biomass cogeneration topic is rather new for Estonia. Many municipalities are interested in installation of cogeneration plants, which will produce heat to cover heat demand and electricity, which can be used for municipality needs or sold. There are no researches in this field in Estonia.

During the research an eligible size for biomass cogeneration capacity in Estonian small towns was defined. Estonian conditions were taken into account: local energy sources, fuel and electricity prices, cold climate, state of local district heating systems, Estonian legislation and support mechanisms for cogeneration plants.

Offered methodology was compared with approach, including maximizing of amount of heat year-round while working at full installed capacity.

Two optimal sizing methods were compared: maximizing of amount of heat year-round while working at full installed capacity and maximizing of amount of heat year-round while working with partial loads. Partial load cogeneration optimal sizing gave better results both from technological, economical and environmental point of view. This optimal sizing for small cities with heat load 5-21 MW results that installed heat capacity for cogeneration plant should be about $37 \%$ from the maximal heat load..

Real installed capacity will depend on the parameters offered by cogeneration equipment producers. Methodology was approbated by economical and environmental factors: NPV and primary energy saving.

Typical towns were chosen for assessment and results can be expanded to all other small towns in Estonia. Results can be used for other Baltic countries and Nordic countries, where cold climate, biomass energy sources and district heating systems are typical.

\section{Acknowledgement}

This work has been partly supported by the European Social Fund within the researcher mobility programme MOBILITAS (2008-2015), 01140B/2009.

\section{References}

[1] Directive 2004/8/EC of the European Parliament and of the Council of 11 February 2004 on the promotion of cogeneration based on a useful heat demand in the internal energy market and amending Directive 92/42/EEC

[2] National Development Plan of the Energy Sector until 2020, Riigikogu, 2009

[3] A.Volkova, E.Latosev, A.Siirde Small-scale CHP potential in Latvia and Estonia, Scientific Proceedings of Riga Technical University, Environmental and Climate Technologies (13), 3th volume, 127-134.

[4] Kris R. Voorspools, William D. D'haeseleer, Reinventing hot water? Towards optimal sizing and management of cogeneration: A case study for Belgium, Applied Thermal Engineering 26 (2006) 1972-1981

[5] Z. Beihong, L. Weiding, An optimal sizing method for cogeneration plants, Energy and Buildings 38 (2006) 189-195.

[6] H.Ren, W.Gao, Y. Ruan, Optimal sizing for residential CHP system, Applied Thermal Engineering 28 (2008) 514-523

[7] A.Vološčuka-Volkova, Operational Analysis of Small-Scale Cogeneration Plants. Optimisation of Capacity Setting. Doctoral Thesis-R.:RTU, 2008.-140 pages

[8] Tveit, T.-M., Savola, T. and Fogelholm, C.-J. 2005. Modelling of steam turbines for mixed integer nonlinear programming (MINLP) in design and off-design conditions of CHP plants, Proceedings of the 46th Conference on Simulation and Modeling (SIMS 2005), 13-14 October 2005, Trondheim, Norway. Trondheim, Tapir Academic Press: 335-344.

[9] Varbanov, P.S., Doyle, S., Smith, R., 2004, Modelling and Optimisation of Utility Systems. Trans IChemE, Chem Eng Res Des, 82(A5): 561-578.

[10] Statistical Database, Statistics Estonia (FE08-2008) Average cost of fuels and energy consumed by enterprises, type of fuel/energy and year, http://pub.stat.ee

[11] Regulation No 30 of the Minister of Economic Affairs and Communications of 3 May 2007 "Requirements for Efficient Cogeneration", Estonia 